The Curse of Natural Resources in Fractionalized Countries

Roland Hodler

04-04

March 2004

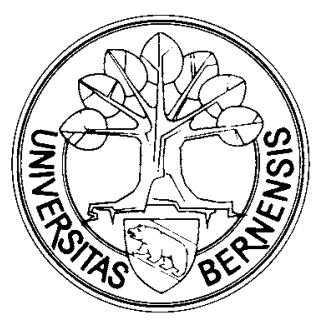

Universität Bern

Volkswirtschaftliches Institut

Gesellschaftstrasse 49

3012 Bern, Switzerland

Tel: 41 (0)31 6314506

Web: www.vwi.unibe.ch 


\title{
The Curse of Natural Resources in Fractionalized Countries
}

\author{
Roland Hodler*
}

March 29, 2004

\begin{abstract}
This paper develops a model that can explain why natural resources are a curse for some countries, but not for others. In this model, natural resources cause fighting activities between rivalling groups. Fighting reduces productive activities and weakens property rights, making productive activities even less attractive. The aggregate production decrease exceeds the natural resources' direct positive income effect if and only if the number of rivalling groups is sufficiently large. The model thus predicts that natural resources lower incomes in fractionalized countries, but increase incomes in homogenous countries. Empirical evidence that supports this hypothesis is provided.
\end{abstract}

Key words: Natural resources; Fractionalization; Rent seeking

JEL classification: Q32; D72

*Economics Department, University of Bern, Vereinsweg 23, CH-3012 Bern, Switzerland, E-mail: roland.hodler@vwi.unibe.ch. Comments are welcome. I would like to thank Ernst Baltensperger, Simon Loertscher, Gerd Muehlheusser and participants at the Annual Congress of the Swiss Society of Economics and Statistics for helpful comments. Any remaining errors are mine. 


\section{Introduction}

Since Sachs and Warner (1995) showed that economic growth is inversely related to various measures of resource abundance, the so-called curse of natural resources has attracted considerable attention in the economic literature. Different empirical studies confirm the findings of Sachs and Warner (1995). Different theoretical contributions suggest explanations why natural resources might be a curse. ${ }^{1}$

In most contributions, examples of countries that seem to suffer from a curse of natural resources are given. Nigeria is often mentioned. Even though it has enjoyed huge oil windfalls since the late 1960s, its per capita GDP in purchasing power parity terms is among the lowest in the world and was even lower in the year 2000 than it was in $1970 .^{2}$ However, Nigeria is not representative for the group of the oil-exporting countries. Many others including Iran, Mexico, Saudi Arabia and Venezuela are considerably less poor and some small oil-rich states are even relatively wealthy. In addition, Norway, one of the world's largest oilexporters, grows at relatively high rates and is among the very richest countries in the world. It is even richer than all its rich neighbors. So, the question arises why oil-rich Norway is so successful while oil-rich Nigeria performs so terribly.

Alternatively, consider the diamond-rich neighbors Angola and Botswana. Average incomes are more than six times higher in Botswana than in Angola and property rights are considerably stronger too. This is hardly surprising since Botswana has been one of the fastest growing countries in the last 40 years while there have been civil wars in Angola most of the time. ${ }^{3}$ But why has diamond-rich Botswana performed so well while diamond-rich Angola has been a disaster even in Sub-Saharan African terms?

Since the focus in the literature is mainly on explaining why natural resources seem to be a curse (with respect to growth), existing contributions are generally not well suited to explain these cross-country differences, i.e., to explain why natural resources seem to be a curse for Angola and Nigeria, but a blessing for Botswana and Norway. Therefore, our goal is to develop a theoretical model that can explain the different impacts of natural resources in these different countries.

This model focuses on rent seeking or, more general, on fighting activities between rivalling groups. Natural resources and other windfall gains lead to an increase in fighting activities if there are multiple rivalling groups. This leads to a direct decrease of productive activities and weakens the property rights. The weaker property rights make productive activities even less attractive such that the aggregate production decrease exceeds the windfall gains' direct positive income effect if the number of rivalling groups is sufficiently large. Thus, natural resources are a curse in countries with many rivalling groups, i.e., in fractionalized countries. This curse becomes more pronounced as fractional-

\footnotetext{
${ }^{1}$ For an overview, see Gylfason (2001) and Sachs and Warner (2001).

${ }^{2}$ For more information on Nigeria, see, e.g., Sala-i-Martin and Subramanian (2003).

${ }^{3}$ For more information on Botswana, see Acemoglu et al. (2003). Note that Angola is not only rich in diamonds, but also in oil.
} 
ization increases. In countries with few rivalling groups, on the other hand, natural resources do not cause much fighting activities such that the positive effect dominates. Natural resources are thus a blessing in such countries.

Our model is closest in spirit to Lane and Tornell (1996) and Tornell and Lane (1999), which also focus on rivalling groups that appropriate unsecured property. ${ }^{4}$ However, there are some noteworthy differences: First, Lane and Tornell assume common access to the whole (formal sector) capital stock; we assume that private property is in general partly protected. Second, windfall gains take exclusively the form of terms of trade shocks in Lane and Tornell's models while they can be of any kind in our model. Third, Lane and Tornell focus on growth and we focus on incomes. Fourth, technological progress has the same (negative) effect as a positive terms of trade shock in their models, but an unambiguously positive effect in our model. Fifth, while economic performance increases in the number of rivalling groups in their models if there are multiple groups, it decreases in the number of rivalling groups in our model.

The paper is structured as follows: Section 2 presents the theoretical model. Section 3 provides some evidence for hypotheses deduced from this model. Among others, it shows that the income effect of natural resources decreases and becomes increasingly negative as ethnic fractionalization increases. In addition, it provides some evidence that the negative growth effect of natural resources might also increase in ethnic fractionalization. Section 4 concludes and highlights that the presented model can account for the different effects of natural resources in, e.g., Nigeria and Norway or in Angola and Botswana.

\section{The Model}

In this section, we present a simple non-cooperative one-shot game that allows analyzing the effects of natural resources and fractionalization on property rights and incomes. First, we explain the setup of the model. Second, we derive the reaction functions. Third, we determine the equilibrium and discuss the results.

\subsection{The Setup}

Given is a country that is endowed with the natural resources $\omega>0$. Somewhat more general, $\omega$ could also include other windfalls gains such as unconditional foreign aid payments.

This country is populated by $n>0$ inhabitants and is endowed with the inputs $X>0$, which might be labor, human capital or physical capital.

\footnotetext{
${ }^{4}$ Lane and Tornell (1996) and Tornell and Lane (1999) look at an economy with multiple groups that have open access to the aggregate capital stock. In these models, each group wants to acquire a greater wealth share by demanding more transfers if the terms of trade improve. The higher transfers increase taxes and reduce the return on capital such that savings decrease in Lane and Tornell (1996). If this negative effect exceeds the direct positive effect of the terms of trade shock, the growth rate decreases. In Tornell and Lane (1999), the lower return on capital leads to a capital reallocation to a less productive informal sector, where capital is safe from taxation. As a consequence, the growth rate decreases.
} 
Further, there are $k \geq 1$ rivalling groups. The number of groups $k$ is taken as exogenous, which corresponds to the assumption that group membership is primarily determined by cultural and historical processes and might not be the result of an optimal choice. This assumption does not seem to be crucial if different groups reflect different ethnic tribes. It might be less innocent if rivalling groups reflect different social classes or even different groups that have been formed for joint rent seeking or joint fighting, respectively.

The $k$ groups are assumed to be equally sized such that each group $i=1 \ldots k$ is endowed with the inputs $x_{i}=\frac{X}{k} .{ }^{5}$ Each group $i$ can allocate its inputs $x_{i}$ to productive activities $l_{i}$ and to fighting activities $f_{i}$. Of course, it must hold that

$$
f_{i}+l_{i}=x_{i}
$$

for all $i=1 \ldots k$.

Each group $i$ makes collectively rational decisions to maximize its income

$$
c_{i}=p y_{i}+r_{i}
$$

where $y_{i}$ denotes the output group $i$ produces and $r_{i}$ the rent it appropriates. But group $i$ can only keep the share $p$, where $0 \leq p \leq 1$, of its production output $y_{i}$. The share $p$ thus measures the effectiveness of the property rights. Somewhat broader, it could be seen as a measure of economic freedom. ${ }^{6}$

Next, we introduce production and appropriation technologies. For simplicity, we assume that the production technology is linear in the productive activities $l_{i}$ such that the production output of group $i$ is given by

$$
y_{i}=a l_{i},
$$

where $a>0$.

Together with the natural resources $\omega$, the shares of the groups' production outputs that are not protected by property rights constitute a common pool. Hence, this pool's content is given by

$$
R=(1-p) \sum_{j=1}^{k} y_{j}+\omega
$$

For the content of this common pool $R$, the $k$ rivalling groups can compete. Thereby, the technology for appropriation from the common pool is such that

\footnotetext{
${ }^{5}$ Fixing the aggregate inputs $X$ and not inputs per group rules out that a certain amount of natural resources $\omega$ has a different effect on a country with few groups than on a country with many groups simply because there are more natural resources relative to aggregate inputs in the former country than in the latter.

${ }^{6}$ Alternatively, $p$ could be replaced by $1-\tau$, where $\tau$ denotes the tax rate. But we prefer a broader interpretation since fighting activities shall not be restricted to take place only on the (legal) political stage in this model.
} 
group $i$ can appropriate the rent ${ }^{7}$

$$
\begin{array}{rlr}
r_{i} & =\frac{1}{k} R \quad \text { if } f_{1}=f_{2}=\ldots=f_{k}=0, \\
& =\frac{f_{i}}{\sum_{j=1}^{k} f_{j}} R & \text { otherwise. }
\end{array}
$$

As the production technology (3) is silent about how productive activities $l_{i}$ are transformed into output $y_{i}$, the appropriation technology (5) is silent about how the rent $r_{i}$ is appropriated. One might think of many different legal and illegal means such as lobbying, bribing, litigations, confiscations, theft or even warfare. To sum up, appropriation can be done by "crime, war, and politics" (Hirshleifer 1994, 2).

Since the property rights variable $p$ measures the production share over which the producing group does not involuntarily lose control, fighting activities $f_{i}$ may well have a negative effect on property rights. Further, it seems plausible that the negative effect of a certain amount of fighting activities tends to be the stronger, the smaller the economy is. Therefore, we assume that the effectiveness of the property rights is determined by

$$
p=1-\frac{1}{X} \sum_{j=1}^{k} f_{j}
$$

This assumption implies that property rights are complete in countries in which no inputs are devoted to rent seeking and fighting activities. Similarly, it implies that property rights are terribly weak or, in fact, non-existent in countries in which there are no engineers and no workers, but only lobbyists and gunmen that try to appropriate resources. The dependence of the property rates' effectiveness $p$ on the input share allocated to fighting activities is assumed to be linear for simplicity.

Of course, property rights might also depend on other factors such as culture, legal traditions and constitutions. However, it is important to take into account that the implementation of constitutions and laws is not exogenous to a society and could thus be influenced by the behavior of powerful groups. As an example, even though "a number of Latin American countries patterned their constitutions after that of the United States" (North 1988, 7), property rights are considerably weaker in these countries than in the United States. Furthermore, we show in appendix A that the results remain similar if property rights depend partly on exogenous factors and if fighting activities have thus a weaker effect on property rights.

\footnotetext{
${ }^{7}$ This technology for appropriation from a common pool is used by Grossman (2001) and might well have been inspired by Tullock (1980). Following Tullock, we could alternatively assume that each group $i$ gets the rent $R$ with probability $q_{i}=\frac{r_{i}}{R}$ and nothing with probability $1-q_{i}$. If the groups were risk neutral, the result would be identical to the subsequently derived except that only expected, but not actual incomes would be the same for all groups. If the groups were risk averse, fighting efforts would be somewhat lower and expected incomes consequently higher.
} 
Next, we solve the model. Thereby, we assume that the $k$ groups play a one-shot Cournot game. Hence, solving the model involves two analytical steps. In a first step, all $k$ groups choose simultaneously how to allocate their inputs $x_{i}$ optimally to productive and fighting activities. This yields each group's reaction function. In a second step, these reaction functions interact to determine the Nash equilibrium, i.e., the equilibrium allocation of each group's inputs, the equilibrium effectiveness of the property rights and the equilibrium incomes.

\subsection{The Reaction Functions}

So, we derive as a first step the reaction function of each group $i$, i.e., the fighting activities $f_{i}$ that maximize the income $c_{i}$ of group $i$ given the other groups' fighting activities. Inserting equations (1), (3), (4), (5) and (6) into equation (2) allows writing the income of group $i$ as

$$
c_{i}=\left(1-\frac{1}{X} f_{-i}\right) a\left(x_{i}-f_{i}\right)+f_{i} \frac{1}{X} a l_{-i}+\frac{f_{i}}{f_{i}+f_{-i}} \omega,
$$

where $f_{-i} \equiv \sum_{j \neq i} f_{j}$ and $l_{-i} \equiv \sum_{j \neq i} l_{j}$. Given equation (7), the reaction function of group $i$ can be shown to be

$$
f_{i}^{R}\left(f_{-i}\right)=\sqrt{\frac{X}{x_{i}} \frac{\omega f_{-i}}{a}}-f_{-i} .
$$

Since $x_{i}=\frac{X}{k}$ for all $i=1 \ldots k$, the reaction function can be simplified to

$$
f_{i}^{R}\left(f_{-i}\right)=\sqrt{\frac{k \omega f_{-i}}{a}}-f_{-i}
$$

\subsection{The Equilibrium}

In a second step, the interaction of all the groups' reaction functions determines the Nash equilibrium.

Since the reaction function (8) holds for each group $i=1 \ldots k$, it must hold in equilibrium that

$$
\sum_{j=1}^{k} f_{j}=\sqrt{\frac{k \omega f_{-i}}{a}}
$$

for all $i=1 \ldots k$. Hence, each group $i$ must choose the same fighting activities $f_{i}^{*}=f^{*}$ in equilibrium. Replacing $f_{i}$ by $f^{*}$ for all $i=1 \ldots k$ in equation (9) and then solving for $f^{*}$ yields each group's equilibrium fighting activities

$$
f^{*}=\frac{(k-1) \omega}{k a}
$$

if

$$
\frac{(k-1) \omega}{k a} \leq \frac{X}{k} \Leftrightarrow(k-1) \omega \leq a X
$$


and $f^{*}=\frac{X}{k}$ otherwise. Subsequently, we assume that condition (11) holds. ${ }^{8}$

Each group's equilibrium fighting activities $f^{*}$ increase therefore in the natural resources $\omega$ and in the number of rivalling groups $k$, but decrease in the productivity $a$.

Equations (6) and (10) imply that the equilibrium effectiveness of the property rights $p^{*}$ is

$$
p^{*}=1-(k-1) \frac{\omega}{a X} .
$$

Hence, property rights tend to be the stronger in equilibrium, the fewer rivalling groups $k$, the less natural resources $\omega$ and the more aggregate inputs $X$ there are. Moreover, technological progress, i.e., an increase in the productivity $a$, also tends to strengthen property rights since it makes productive activities more attractive relative to fighting activities. ${ }^{9}$

Equations (1), (7) and (10) imply that each group's equilibrium income is

$$
c^{*}=\frac{1}{k}[a X-(k-2) \omega] .
$$

Consequently, equilibrium per capita incomes are

$$
\bar{c}^{*}=\frac{k c^{*}}{n}=\frac{1}{n}[a X-(k-2) \omega] .
$$

Let us now discuss how these equilibrium incomes depend on the different parameters. First, an increase in the number of rivalling groups $k$ decreases group incomes $c^{*}$ and per capita incomes $\bar{c}^{*}$ since it increases the input shares allocated to fighting activities. Hence, incomes would be highest if $k=1$ or, alternatively, if the $k>1$ different groups colluded successfully.

Second, the income effect of the natural resources $\omega$ decreases in the number of rivalling groups $k$. It is positive if $k<k^{\text {crit }}$, where $k^{\text {crit }}=2$, and becomes increasingly negative if $k>k^{\text {crit }} .{ }^{10}$ Hence, natural resources are a curse in relatively fractionalized countries, but a blessing in relatively homogenous countries.

Third, technological progress increases equilibrium incomes.

Fourth, a rise in the aggregate inputs $X$ increases the group incomes $c^{*}$. Its effect on per capita incomes $\bar{c}^{*}$ depends on the source of this rise. If $X$ rises since each inhabitant becomes better endowed (such that $\frac{X}{n}$ increases), $\bar{c}^{*}$ increases. If $X$ rises due to an increase in the population size $n$ (such that $\frac{X}{n}$ remains unchanged), the effect of natural resources $\omega$ on $\bar{c}^{*}$ becomes weaker. Thus, $\bar{c}^{*}$ increases (decreases) in this case if $k>(<) k^{\text {crit }}$.

\footnotetext{
${ }^{8}$ If condition (11) did not hold, the equilibrium effectiveness of the property rights would be $p^{*}=0$ and each group's equilibrium income $c^{*}=\frac{\omega}{k}$.

${ }^{9}$ The importance of strong property rights for technological and economic progress is well established in the literature. Complementary, this model suggests that causation could also be reverse: Technological progress could strengthen property rights.

${ }^{10}$ Appendix A shows that the threshold $k^{c r i t}$ is the higher, the weaker the effect of fighting activities on property rights is.
} 


\section{$3 \quad$ Empirical Evidence}

The theoretical model presented in section 2 suggests, among others, the following two hypotheses: First, property rights are negatively affected by the number of rivalling groups and by the amount of natural resources relative to aggregate inputs. Second, the effect of natural resources on incomes is the worse, the more rivalling groups there are, i.e., the more fractionalized the country is.

In this section, we first discuss some measurement issues and provide then evidence supporting these two hypotheses. Further, we test whether the growth effect of natural resources also tends to become worse as fractionalization increases.

\subsection{Measurement Issues}

Testing the abovementioned hypotheses requires, among others, proxies for the natural resources, for the number of rivalling groups and for the property rights' effectiveness. Since measuring these variables adequately seems difficult and maybe even controversial, we discuss the proxies we use. ${ }^{11}$

\subsubsection{Measuring Natural Resources}

In the literature, many different measures of natural resources have been used. Most of them, including the shares of primary exports or of mineral production in either GDP or total exports, focus on natural resources that are currently extracted or currently exported, respectively. But the rivalling groups' behavior in general and their fighting in particular depend most likely on actual as well as on potential rents and, consequently, not only on the natural resources that are currently extracted or exported. Therefore, we follow Gylfason (2001) and use proxies that are based on the World Bank (1997) report "Expanding the Measure of Wealth", which includes natural resources that can, in expectation, be extracted in the future. ${ }^{12}$ This report estimates physical, human and natural capital of 92 countries.

Gylfason (2001) uses the share of natural capital in the sum of physical, human and natural capital $(N C S)$, which might be a good proxy for natural resources relative to aggregate inputs. As proxy for the natural resources $\omega$, we use per capita natural capital $(N C)$. Unlike $N C S, N C$ does not tend to be lower in developed countries than in developing countries with the same natural capital. Further, we use the estimates of per capita physical and human capital $(P H C)$ as proxy for the productivity-adjusted per capita inputs $\frac{a X}{n}$.

In addition, we will use the share of primary exports in total exports $(P X I)$ in section 3.4.

\footnotetext{
${ }^{11}$ In addition, appendix B briefly describes all variables used in the subsequently presented regressions.

${ }^{12}$ We are grateful to Thorvaldur Gylfason who mailed us the corresponding data file.
} 


\subsubsection{Measuring Fractionalization}

Measuring the number of rivalling groups in a certain country is difficult, especially, since countries might be divided into different groups for various reasons. Different groups might reflect, e.g., different social classes, different interest groups or different ethnic tribes.

Income and wealth inequality measures like Gini coefficients might be useful to proxy the likelihood that there are at least two different social classes. But they do not provide much information about the number of different social classes. ${ }^{13}$ Further, there seems to be no measure that could appropriately capture fractionalization that is due to different groups that have been formed for joint rent seeking or joint fighting, respectively.

Given these difficulties, we prefer to focus on ethnic fragmentation. We therefore use the index of ethnic fractionalization $(E T H N)$ as proxy for the number of rivalling groups $k$. This index measures the probability that two randomly selected individuals of a certain country belong to different ethnic groups. Alesina et al. (2003) provide ETHN for all 92 countries that are included in the World Bank (1997) report.

Further, Alesina et al. (2003) provide an index of linguistic fractionalization $(L A N G)$ and an index of religious fractionalization $(R E L)$. We use these indices to check the robustness of some results we obtain with $E T H N$.

\subsubsection{Measuring Property Rights}

Quantifying property rights is difficult too. Nevertheless, the Heritage Foundation and the Fraser Institute provide indices of economic freedom that rate, among others, property rights.

The Heritage Foundation's "2003 Index of Economic Freedom" (O'Driscoll et al. 2003) assesses economic freedom in 156 countries. Among those are all countries included in the World Bank (1997) report, except Burundi and Papua New Guinea. The Heritage Foundation rates ten categories important for economic freedom, including property rights, with a score between 1 and 5 with low scores standing for institutions and policies that support economic freedom. The average score yields the index of economic freedom.

Since the property rights variable $p$ of the theoretical model seems close in its meaning to the Heritage Foundation's rating of the property rights $(P R H)$ and to its index of economic freedom $(E F H)$, we use $P R H$ as well as $E F H$.

The Fraser Institute's "Economic Freedom of the World: 2003 Annual report" (Gwartney and Lawson 2003) assesses economic freedom in, among others, 85 countries included in the World Bank (1997) report. It incorporates components of five categories including "the legal structure and the security of property rights" $(P R F)$. Each category is ranked with a score between 1 and 10 with

\footnotetext{
${ }^{13}$ The relationship between the number of different social classes and the Gini coefficient, for instance, might well be hump-shaped. If the Gini coefficient is zero, there is only one social class. If it is one, there are exactly two different social classes (with the upper class counting only one member). However, if the Gini coefficient is in-between, there might well be more than two different social classes.
} 
high scores implying institutions and policies that support economic freedom. Again, the average score yields the economic freedom rating $(E F F)$. Subsequently, we use $P R F$ and $E F F$ to check the robustness of results we obtain with $P R H$ and $E F H$.

\subsection{Estimating Property Rights}

The theoretical model or equation (12), to be more precise, suggests that property rights are the stronger, the fewer rivalling groups and the less natural resources relative to the productivity-adjusted aggregate inputs there are. In this section, we provide evidence that supports this hypothesis. But we also mention that some results could be driven by the omission of geographical variables.

Columns (1.1) and (2.1) on tables 1 and 2 present the results from regressing $P R H$ and EFH on ETHN and NCS. All coefficients have the predicted positive sign and are economically as well as statistically significant. These findings suggest that property rights and economic freedom are indeed inversely related to (ethnic) fractionalization and to the amount of natural resources relative to aggregate inputs. These results are consistent with the theoretical model's prediction.

The remaining columns on tables 1 and 2 suggest that these findings are fairly robust. Columns (1.2) and (2.2) show that the coefficients on NCS and $E T H N$ still have the predicted sign and are still significant if we replace $P R H$ and $E F H$ by $P R F$ and EFF. ${ }^{14}$ Columns (1.3) and (2.3) imply that the results do not change considerably if we replace $E T H N$ by $L A N G .{ }^{15}$ In columns (1.4) and (2.4), we replace $N C S$ by $\frac{N C}{P H C}$ since the latter might be an even more accurate proxy for the natural resources relative to aggregate inputs, which equation (12) suggests to be relevant. The results remain significant.

However, the significant negative association between property rights and (ethnic) fractionalization might just be the result of omitting geographical variables. La Porta et al. (1999) find that ethnolinguistic fractionalization has a negative effect on property rights, which becomes insignificant if they control for GNP per capita and for absolute latitude $(L A T I)$, i.e., the distance from the equator. Similarly, the negative effect of ETHN and $L A N G$ on property rights becomes also insignificant in Alesina et al. (2003) if they control for $L A T I$. The same holds true if we control for $L A T I$ in the regressions presented in this section. That is, the coefficients on fractionalization become insignificant. Therefore, (ethnic) fractionalization might only be significantly related to property rights and economic freedom since it captures some geographic characteristics that directly affect property rights and economic freedom. ${ }^{16}$

\footnotetext{
${ }^{14}$ Remember that institutions and policies that support economic freedom get low scores in the Heritage Foundation's report, but high scores in the Fraser Institute's report.

${ }^{15}$ The effects of $R E L$ on $P R H$ and on $E F H$ would be insignificant. The reason could be that measured religious fractionalization is often low in unfree societies, as Alesina et al. (2003) argue.

${ }^{16}$ But "while one can think of several reasons why ethnic conflict may affect (...) institutions, the relationship between latitude and (...) the protection of property rights seems much less obvious" (Alesina et al. 2003, 169). Thus, LATI could just capture some effects of ETHN
} 


\subsection{Estimating the Income Effect of Natural Resources}

The theoretical model or equation (13), to be more precise, implies that per capita incomes increase in the productivity-adjusted per capita inputs and that the income effect of natural resources is positive in homogenous countries, but becomes increasingly negative as the number of rivalling groups increases. In this section, we provide evidence that supports these predictions. In particular, we show that the income effect of natural resources becomes worse as ethnic fractionalization increases.

Thereby, we measure incomes by the World Bank's (2003) per capita gross national incomes in the year 2000 in purchasing power parity terms $(G N I P)$. Further, we use per capita gross national incomes derived by the Atlas methodology $(G N I A)$ to check the robustness of our findings. In addition, we use the dummy variable $F R A C$, which is one for countries with $E T H N$ larger than the mean and zero otherwise. ${ }^{17}$

All columns on table 3 show that the association between $P H C$, which serves as proxy for the productivity-adjusted per capita inputs, and GNIP is positive and highly significant. This finding, which the model predicts and common sense suggests, holds in all regressions presented in this section.

Column (3.1) shows that the association between NC and GNIP is slightly positive, but insignificant in the group of the ethnically homogenous countries while it is negative in the group of the ethnically fractionalized countries. Further, it shows that the effect of $N C$ on GNIP is significantly more negative in the fractionalized countries than in the homogenous countries.

The remaining columns provide further evidence that fractionalization worsens the income effect of natural resources. In the regression presented in column (3.2), the coefficient on $N C$ is significantly positive while the coefficient on the interaction term $E T H N * N C$ is significantly negative and about three times larger in absolute values. This implies that natural resources have a positive effect on incomes in ethnically very homogenous countries, but that this effect decreases in ETHN and becomes zero if ETHN is about one third. As $E T H N$ increases further, the income effect of natural resources becomes increasingly negative. Column (3.3) shows that the coefficients on $N C$ and on the interaction term remain similar if we control for ETHN. In addition, columns (3.4) and (3.5) show that the income effect of natural resources also decreases in linguistic and religious fractionalization.

Table 4 shows that the finding that the income effect of natural resources decreases in (ethnic) fractionalization is fairly robust. If we replace GNIP by $G N I A$, the interaction terms between fractionalization and $N C$ become even significant at a $1 \%$ level in all specifications discussed above. Interestingly, the same holds true if we control LATI and the interaction term LATI*NC. Further, the interaction terms between fractionalization and $N C$ become also

on property rights since the correlation between ETHN and LATI is - 0.53 in the sample of the 92 countries included in World Bank (1997).

${ }^{17}$ The presented results would not change if $F R A C$ were equal to one for countries with $E T H N$ larger than the median and zero otherwise. 
significant at a $1 \%$ level if we omit the developed countries and restrict the sample to the 68 countries that are not members of the OECD. ${ }^{18}$

So, we find that incomes are positively related to physical and human capital and, in ethnically homogenous countries, also to natural resources. Further, the income effect of natural resources seems to decrease and to become increasingly negative as (ethnic) fractionalization increases. These findings are consistent with the theoretical model's predictions.

\subsection{Estimating the Growth Effect of Natural Resources}

Since the theoretical model presented in section 2 is a one-shot game, there can be no direct implications for growth. Nevertheless, we test in this section whether the growth effect of natural resources becomes also worse as (ethnic) fractionalization increases.

Sachs and Warner (1995) and many others use PXI to show that natural resources have a negative effect on growth rates. We use $P X I$ to test whether the negative growth effect of natural resources becomes larger as ETHN increases. We base this test on Sachs and Warner (1997), which is a revised version of Sachs and Warner (1995), and their data. Column (5.1) on table 5 replicates their regression (3.3). It implies that $P X I$ is inversely related to the growth rate even if it is controlled for initial GDP, openness, capital accumulation, institutional quality and the development of the terms of trade. ${ }^{19}$

In column (5.2), we add the interaction term ETHN*PXI. The effect of $P X I$ on the growth rate turns out to be insignificant in ethnically very homogenous countries, but to become increasingly negative as ETHN increases.

As column (5.3) shows, the negative growth effect of $P X I$ increases significantly in $E T H N$ even if we control for $E T H N$. Hence, ethnic fractionalization might not only lower growth since it deteriorates public policy as suggested by Easterly and Levine (1997), but also because it makes the growth curse of natural resources worse.

However, this finding is not very robust. If we replace, e.g., ETHN by $L A N G$ or PXI by the share of primary exports in GDP, the coefficients on the interaction term and on fractionalization both become insignificant. ${ }^{20}$

So, there is some first, but not yet conclusive evidence that the growth curse of natural resources might also become worse as (ethnic) fractionalization increases.

\footnotetext{
${ }^{18}$ Further, the negative association between NCS and GNIP, which Gylfason (2001) finds, becomes also significantly more negative as (ethnic) fractionalization increases. But since the negative association between $N C S$ and GNIP is primarily caused by a positive association between $P H C$ and $G N I P$, it is not obvious whether this finding also suggests that the income effect of natural resources becomes worse as (ethnic) fractionalization increases.

${ }^{19}$ For more information on the variables used, see appendix B or Sachs and Warner (1997).

${ }^{20}$ Since $N C S$ is not available for past times, replacing $P X I$ by $N C S$ would lead to results that are difficult to interpret. In particular, the association between $N C S$ and the growth rate could be negative simply because $N C S$ tends to be higher in slow growing countries.
} 


\section{Conclusions}

Remember that our goal is to explain why the impact of natural resources might differ in different resource-rich countries such as Nigeria and Norway.

Nigeria is among the most fractionalized countries in the world with ethnic fractionalization, as measured by the index of ethnic fractionalization, equal to 0.85. The different rivalling groups include the Hausa, the Yoruba and the Igbo. Further, there are at least seven other ethnic groups with more than two million members. The presented theoretical model suggests that oil windfalls cause intensive fighting in such a fractionalized country. Further, it predicts that this fighting weakens the property rights and lowers incomes since the production decrease, which the fighting causes, exceeds the positive income effect of the oil windfalls. Hence, the model predicts intensive fighting, weak property rights and low per capita incomes for such a fractionalized, oil-rich country as Nigeria. It is a tragedy that the reality confirms these predictions.

In Norway, on the other hand, ethnic fractionalization is only 0.06 since almost everybody (97 per cents) belongs to the same ethnic group. Furthermore, there are neither class struggles nor other reasons for social fragmentation. For such a homogenous country, the theoretical model predicts that oil windfalls should not cause much fighting. Hence, property rights should be effective and the oil windfalls a blessing. Fortunately, these predictions fit the reality. ${ }^{21}$

Similarly, the model suggests that the much higher fighting intensity, the weaker property rights and the much lower incomes in diamond-rich Angola than in diamond-rich Botswana could be related to the fact that ethnic fractionalization is almost twice as high in Angola (0.79) as in Botswana (0.41), which is among the ethnically least fractionalized countries in Sub-Saharan Africa. ${ }^{22}$

In addition to these casual observations, we have provided systematical empirical support for the theoretical model's predictions. In particular, we have shown that the effect of natural resources on incomes is positive in ethnically homogenous countries, but becomes increasingly negative as ethnic fractionalization increases. Hence, theory, empirical evidence and casual observations suggest that natural resources tend to be a blessing with respect to incomes in homogenous countries, but a curse in fractionalized countries.

There is some first evidence that the growth curse of natural resources might also increase in ethnic fractionalization. To what extent this holds remains an open question for future research.

Finally, the presented model offers policy implications that follow from the similarity between natural resource windfalls and foreign aid windfalls: Foreign aid payments might weaken property rights and reduce incomes in highly fractionalized countries. Whether aid effectiveness depends indeed on fraction-

\footnotetext{
${ }^{21}$ In all other oil-exporting countries, ethnic fractionalization is considerably higher than in Norway, but lower than in Nigeria. The presented model suggests that this might be the reason why all other oil-exporting countries perform worse than Norway, but most of them considerably better than Nigeria.

${ }^{22}$ Sierra Leone is another ethnically highly fractionalized (0.82), diamond-rich country with an extraordinary poor performance.
} 
alization is another open question for future research. Svensson's (2000) finding that foreign aid increases corruption only in ethnically fractionalized countries indicates that this might well be the case. However, aid payments to a fractionalized country could potentially be successful if they were truly conditional on cooperation among this country's rivalling groups. Such an aid policy would make collusion more attractive for the different groups. 


\section{Appendices}

\subsection{Appendix A}

In section 2, we solve the theoretical model under the assumption that the property rights' effectiveness is determined by equation (6). In this appendix, we show that the results remain similar even if the effect of fighting activities on property rights is considerably weaker, but non-zero.

Let us assume that the effectiveness of the property rights is given by

$$
p=(1-\lambda) \bar{p}+\lambda\left(1-\frac{\sum_{i=1}^{k} f_{i}}{X}\right),
$$

where $0 \leq \bar{p} \leq 1$ and $0<\lambda \leq 1$. So, property rights still depend negatively on the input share that is allocated to fighting activities, but this dependence is now weaker (unless $\lambda=1$ ). The exogenous component $\bar{p}$ might well represent factors such as culture, legal traditions and constitutions.

By proceeding as in section 2, each group's equilibrium fighting effort can be shown to be

$$
f^{*}=\frac{(k-1)\left[(1-\lambda)(1-\bar{p}) X+\frac{\omega}{a}\right]}{k[k-(k-1) \lambda]} .
$$

Inserting $f^{*}$ into equation (14) would allow showing that the equilibrium effectiveness of the property rights $p^{*}$ is still increasing in $a$ and $X$ as well as decreasing in $k$ and $\omega$.

Further, it can be shown that the equilibrium per group income is

$$
c^{*}=\frac{\{k-(k-1)[\lambda+(1-\lambda)(1-\bar{p})]\} a X+[1-(k-1) \lambda] \omega}{[k-(k-1) \lambda] k} .
$$

Changes in $a, k$ and $X$ can be shown to have qualitatively the same effects on equilibrium incomes as in section 2. In addition, equilibrium incomes increase (decrease) in the natural resources $\omega$ if and only if the number of rivalling groups $k<(>) k^{c r i t}$, where $k^{\text {crit }}=\frac{1+\lambda}{\lambda}$. Hence, the threshold $k^{\text {crit }}$ decreases in $\lambda$. That is, it is the higher, the weaker the effect of fighting activities on property rights is. Nevertheless, the income effect of the natural resources $\omega$ becomes still negative if $k$ becomes sufficiently large. But if property rights were fully exogenous, i.e., if $\lambda=0$, natural resources $\omega$ would always have a positive effect on incomes independent of $k$.

\subsection{Appendix B}

\subsubsection{Data Sources for Tables 1-4}

In this appendix, we briefly describe the variables we use in the regressions presented on the tables 1 to 4 . 
NCS: The share of natural capital in the sum of physical, human and natural capital in the year 1994, i.e., $\frac{N C}{N C+P H C}$. Source: World Bank (1997)

NC: The per capita natural capital in the year 1994 in thousand US dollars based on purchasing power parity and given a $4 \%$ discount rate. Source: World Bank (1997)

PHC: The sum of per capita physical and human capital in the year 1994 in thousand US dollars based on purchasing power parity and given a $4 \%$ discount rate. Source: World Bank (1997)

ETHN: The index of ethnic fractionalization. Source: Alesina et al. (2003)

FRAC: A dummy variable that is equal to 1 for countries with $E T H N$ larger than the mean and 0 otherwise.

LANG: The index of linguistic fractionalization. Source: Alesina et al. (2003)

REL: The index of religious fractionalization. Source: Alesina et al. (2003)

EFH: The index of economic freedom of the Heritage Foundation. Source: O'Driscoll et al. (2003)

PRH: The rating of the property rights of the Heritage Foundation. Source: O'Driscoll et al. (2003)

EFF: The summary economic freedom rating of the Fraser Institute. Source: Gwartney and Lawson (2003)

PRF: The rating of "the legal structure and the security of property rights" of the Fraser Institute. Source: Gwartney and Lawson (2003)

GNIP: The per capita gross national income in the year 2000 in thousand international dollars based on purchasing power parity. Source: World Bank (2003)

GNIA: The per capita gross national income in the year 2000 in thousand US dollars derived by the Atlas methodology. Source: World Bank (2003)

LATI: The absolute value of the latitude, scaled to take values between 0 and 1. Source: La Porta et al. (1999) 


\subsubsection{Data Sources for Table 5}

In this appendix, we briefly describe the variables we use in the regressions presented on table 5. All variables, except ETHN, are taken from Sachs and Warner (1997). Thus, see there for additional information.

Growth Rate: The average annual growth in real GDP divided by the economically active population from 1970 to 1990 .

PXI: The ratio of primary exports to total merchandising exports in 1970.

LGDP: The log of real GDP divided by the economically active population in 1970 .

SOPEN: The fraction of years over the period 1970-1990 in which the country is rated as economically open.

LINV: The log of the ratio of real gross domestic investment to real GDP, averaged over the period 1970-1989.

RL: The rule of law index from the International Country Risk Guide.

DTT: The average annual growth rate in the log of the external terms of trade between 1970 and 1990. External terms of trade are defined as the ratio of an export price index to an import price index.

ETHN: The index of ethnic fractionalization. Source: Alesina et al. (2003) 


\section{References}

[1] Acemoglu, Daron, Simon Johnson and James A. Robinson (2003), Botswana: An African Success Story, in: Dani Rodrik (ed.), In Search of Prosperity. Princeton University Press, Princeton, New Jersey, 80-119.

[2] Alesina, Alberto, Arnaud Devleeschauwer, William Easterly, Sergio Kurlat and Romain Wacziarg (2003), Fractionalization. Journal of Economic Growth, 8 (2), 155-194.

[3] Easterly, William and Ross Levine (1997), Africa's Growth Tragedy: Policies and Ethnic Divisions. Quarterly Journal of Economics, 111(4), 12031250.

[4] Grossman, Herschel I. (2001), The Creation of Effective Property Rights. American Economic Review, 91 (2), 347-352.

[5] Gwartney, James and Robert Lawson (2003), Economic Freedom of the World: 2003 Annual report. Fraser Institute, Vancouver.

[6] Gylfason, Thorvaldur (2001), Natural Resources, Education, and Economic Development. European Economic Review, 45 (4-6), 847-859.

[7] Hirshleifer, Jack (1994), The Dark Side of the Force. Economic Inquiry, 32 (1), 1-10.

[8] Lane, Philip R. and Aaron Tornell (1996), Power, Growth and the Voracity Effect. Journal of Economic Growth, 1 (2), 213-241.

[9] La Porta, Rafael, Florencio Lopez-de-Silanes, Andrei Shleifer and Robert Vishney (1999), The Quality of Government. The Journal of Law, Economics and Organization, 15 (1), 222-279.

[10] North, Douglass C. (1988), Institutions, Economic Growth and Freedom: An Historical Introduction, in: Michael Walker (ed.), Freedom, Democracy and Economic Welfare. Fraser Institute, Vancouver, 3-25.

[11] O'Driscoll, Gerald P., Edwin J. Feulner and Mary Anastasia O'Grady (2003), 2003 Index of Economic Freedom. Heritage Foundation, Washington, DC.

[12] Sachs, Jeffrey D. and Andrew M. Warner (1995), Natural Resource Abundance and Economic Growth. NBER Working Paper 5398.

[13] Sachs, Jeffrey D. and Andrew M. Warner (1997), Natural Resource Abundance and Economic Growth (revised version). Harvard Institute for International Development, Cambridge, MA.

[14] Sachs, Jeffrey D. and Andrew M. Warner (2001), The Curse of Natural Resources. European Economic Review, 45 (4-6), 827-838. 
[15] Sala-i-Martin, Xavier and Arvind Subramanian (2003), Addressing the Natural Resource Curse: An Illustration from Nigeria. NBER Working Paper 9804.

[16] Svensson, Jakob (2000), Foreign Aid and Rent-Seeking. Journal of International Economics, 51 (2), 437-461.

[17] Tornell, Aaron and Philip R. Lane (1999), The Voracity Effect. American Economic Review, 89 (1), 22-46.

[18] Tullock, Gordon (1980), Efficient Rent Seeking, in: James M. Buchanan, Robert D. Tollison and Gordon Tullock (eds.), Toward a Theory of the Rent Seeking Society. Texas A\&M University Press, College Station, 97-112.

[19] World Bank (1997), Expanding the Measure of Wealth. Environmentally Sustainable Development Studies and Monographs Series 17, World Bank, Washington, DC.

[20] World Bank (2003), World Development Indicators 2003. World Bank, Washington, DC. 
Table 1: Estimating Property Rights

\begin{tabular}{lllll} 
Column: & 1.1 & 1.2 & 1.3 & 1.4 \\
ETHN & $\begin{array}{l}1.340^{* * *} \\
(0.454)\end{array}$ & $\begin{array}{l}-2.207^{* *} \\
(0.915)\end{array}$ & & $\begin{array}{l}1.511^{* * *} \\
(0.430)\end{array}$ \\
LANG & & & $\begin{array}{l}0.711^{* *} \\
(0.335)\end{array}$ & \\
NCS & $\begin{array}{l}2.815^{* * *} \\
(1.000)\end{array}$ & $\begin{array}{l}-4.014^{* *} \\
(1.930)\end{array}$ & $\begin{array}{l}3.710^{* * *} \\
(0.974)\end{array}$ & \\
& & & & $1.209 * *$ \\
NC/PHC & & & & $(0.471)$ \\
Intercept & $1.991^{* * *}$ & $6.874 * * *$ & $2.171^{* * *}$ & $2.058^{* * *}$ \\
& $(0.235)$ & $(0.439)$ & $(0.198)$ & $(0.239)$ \\
Observations & 90 & 85 & 87 & 90 \\
R-squared & 0.241 & 0.184 & 0.210 & 0.222 \\
\hline
\end{tabular}

Dependent variable: PRH in columns 1.1, 1.3 and 1.4; PRF in column 1.2.

White Heteroskedasticity-Consistent Standard Errors in parentheses.

$*, * *, * * *$ indicates significance at a $10 \%, 5 \%, 1 \%$ level.

\section{Table 2: Estimating Economic Freedom}

\begin{tabular}{lllll} 
Column: & 2.1 & 2.2 & 2.3 & 2.4 \\
ETH & $0.594 * *$ & $-0.918^{* *}$ & & $0.685^{* * * *}$ \\
& $(0.219)$ & $(0.372)$ & & $(0.210)$ \\
LANG & & & $0.524 * * *$ & \\
& & & $(0.162)$ & \\
NCS & $1.547 * * *$ & $-3.060^{* * *}$ & $1.644 * * *$ & \\
& $(0.489)$ & $(0.935)$ & $(0.454)$ & \\
NC/PHC & & & & $0.674^{* * *}$ \\
& & & & $(0.243)$ \\
Intercept & $2.428^{* * *}$ & $7.188^{* * *}$ & $2.467 * * *$ & $2.465 * * *$ \\
& $(0.119)$ & $(0.153)$ & $(0.095)$ & $(0.120)$ \\
Observations & 90 & 85 & 87 & 90 \\
R-squared & 0.235 & 0.281 & 0.243 & 0.212 \\
\hline
\end{tabular}

Dependent variable: ERH in columns 2.1, 2.3 and 2.4; ERF in column 2.2.

White Heteroskedasticity-Consistent Standard Errors in parentheses.

$*, * *, * * *$ indicates significance at a $10 \%, 5 \%, 1 \%$ level. 
Table 3: Estimating Incomes

\begin{tabular}{|c|c|c|c|c|c|}
\hline Column: & 3.1 & 3.2 & 3.3 & 3.4 & 3.5 \\
\hline $\mathrm{NC}$ & $\begin{array}{l}0.026 \\
(0.023)\end{array}$ & $\begin{array}{l}0.082 * * * \\
(0.027)\end{array}$ & $\begin{array}{l}0.075 * * \\
(0.032)\end{array}$ & $\begin{array}{l}0.048 \\
(0.029)\end{array}$ & $\begin{array}{l}0.068 * * * \\
(0.025)\end{array}$ \\
\hline FRAC*NC & $\begin{array}{l}-0.106^{* * *} \\
(0.043)\end{array}$ & & & & \\
\hline ETHN*NC & & $\begin{array}{l}-0.247 * * \\
(0.099)\end{array}$ & $\begin{array}{l}-0.224 * \\
(0.121)\end{array}$ & & \\
\hline LANG*NC & & & & $\begin{array}{l}-0.189 * \\
(0.102)\end{array}$ & \\
\hline $\mathrm{REL} * \mathrm{NC}$ & & & & & $\begin{array}{l}-0.144 * * * \\
(0.044)\end{array}$ \\
\hline PHC & $\begin{array}{l}0.094 * * * \\
(0.002)\end{array}$ & $\begin{array}{l}0.093 * * * \\
(0.002)\end{array}$ & $\begin{array}{l}0.092 * * * \\
(0.002)\end{array}$ & $\begin{array}{l}0.095 * * * \\
(0.002)\end{array}$ & $\begin{array}{l}0.095 * * * \\
(0.002)\end{array}$ \\
\hline ETHN & & & $\begin{array}{l}-0.417 \\
(0.742)\end{array}$ & & \\
\hline LANG & & & & $\begin{array}{l}0.824 \\
(0.627)\end{array}$ & \\
\hline REL & & & & & $\begin{array}{l}0.838 \\
(0.644)\end{array}$ \\
\hline Intercept & $\begin{array}{l}-0.181 \\
(0.187)\end{array}$ & $\begin{array}{l}-0.104 \\
(0.221)\end{array}$ & $\begin{array}{l}-0.109 \\
(0.365)\end{array}$ & $\begin{array}{l}-0.700 * \\
(0.367)\end{array}$ & $\begin{array}{l}-0.852^{* *} \\
(0.356)\end{array}$ \\
\hline Observations & 92 & 92 & 92 & 89 & 92 \\
\hline$\underline{\mathrm{R} \text {-squared }}$ & 0.977 & 0.978 & 0.978 & 0.975 & 0.976 \\
\hline
\end{tabular}

Dependent variable: GNIP. White Heteroskedasticity-Consistent Standard Errors in parentheses. $*, * *, * * *$ indicates significance at a $10 \%, 5 \%, 1 \%$ level.

Table 4: Modifications and the Interaction terms

\begin{tabular}{llllll} 
Column: & 4.1 & 4.2 & 4.3 & 4.4 & 4.5 \\
\hline Row A: & $-0.106 * *$ & $-0.247 * *$ & $-0.224 *$ & $-0.189 *$ & $-0.144 * * *$ \\
Results from table 3 & $(0.043)$ & $(0.099)$ & $(0.121)$ & $(0.102)$ & $(0.044)$ \\
Row B: & $-0.140^{* * *}$ & $-0.385^{* * *}$ & $-0.583 * * *$ & $-0.571 * * *$ & $-0.370^{* * *}$ \\
GNIA as dep. var. & $(0.052)$ & $(0.130)$ & $(0.186)$ & $(0.164)$ & $(0.095)$ \\
Row C: & $-0.093 * * *$ & $-0.264 * * *$ & $-0.281 * * *$ & $-0.244 * * *$ & $-0.184 * * *$ \\
Control for LATI & $(0.031)$ & $(0.048)$ & $(0.057)$ & $(0.092)$ & $(0.067)$ \\
Row D: & $-0.119 * * *$ & $-0.249 * * *$ & $-0.247 * * *$ & $-0.226 * * *$ & $-0.294 * * *$ \\
Non-OECD sample & $(0.021)$ & $(0.050)$ & $(0.078)$ & $(0.082)$ & $(0.101)$ \\
\hline
\end{tabular}

This table reports interaction terms after certain modifications of the setting from table 3 . This interaction term is FRAC*NC in column 4.1, ETHN*NC in 4.2 and 4.3 , LANG*NC in 4.4 and REL*NC in 4.5. Thereby, it is controlled for ETHN in column 4.3, for LANG in 4.4, for REL in 4.5 and for PHC and an intercept in all columns. Row A replicates the results of table 3. In row B, GNIA replaces GNIP as dependent variable. In row C, it is controlled for LATI and LATI*NC. In row D, the sample is restricted to the 68 non-OECD countries.

White Heteroskedasticity-Consistent Standard Errors in parentheses.

$*, * *, * * *$ indicates significance at a $10 \%, 5 \%, 1 \%$ level. 
Table 5: Estimating the Growth Rate

\begin{tabular}{llll} 
Column & 5.1 & 5.2 & 5.3 \\
\hline PXI & $-2.497 * * *$ & -1.206 & -0.543 \\
& $(0.642)$ & $(0.770)$ & $(0.914)$ \\
ETHN*PXI & & $-2.489 * * *$ & $-4.312^{* *}$ \\
& & $(0.807)$ & $(2.028)$ \\
LGDP & $-1.795^{* * *}$ & $-2.003 * * *$ & $-2.045^{* * *}$ \\
& $(0.248)$ & $(0.243)$ & $(0.247)$ \\
SOPEN & $1.359 * * *$ & $1.546^{* * *}$ & $1.609 * * *$ \\
& $(0.491)$ & $(0.466)$ & $(0.471)$ \\
LINV & $0.646^{*}$ & 0.489 & 0.455 \\
& $(0.379)$ & $(0.360)$ & $(0.362)$ \\
RL & $0.354 * * *$ & $0.370^{* * *}$ & $0.376^{* * *}$ \\
& $(0.127)$ & $(0.120)$ & $(0.112)$ \\
DTT & $0.157 * * *$ & $0.197 * * *$ & $0.202 * * *$ \\
& $(0.055)$ & $(0.054)$ & $(0.054)$ \\
ETHN & & & 1.526 \\
& & & $(1.557)$ \\
Intercept & $14.76^{* * *}$ & $16.67 * * *$ & $16.71 * * *$ \\
& $(2.051)$ & $(2.027)$ & $(2.028)$ \\
Observations & 73 & 73 & 73 \\
R-squared & 0.660 & 0.704 & 0.708 \\
\hline
\end{tabular}

Dependent variable: Growth rate. OLS regressions.

Standard Errors in parentheses.

$*, * *, * * *$ indicates significance at a 10\%, 5\%, $1 \%$ level. 